\title{
Fetal marrow suppression after maternal chemotherapy for leukaemia
}

\author{
N A Murray, D Acolet, M Deane, J Price, I A G Roberts
}

\begin{abstract}
A preterm baby, whose mother received chemotherapy for acute leukaemia during pregnancy, required intensive care because of profound anaemia and neutropenia. Haemopoietic progenitor cell studies showed fetal marrow suppression. Those caring for such mothers and babies should know the possible serious effects chemotherapy for malignancies can have on a developing fetus. Long term follow up of the baby is imperative.
\end{abstract}

(Arch Dis Child 1994; 71: F209-F210)

Acute leukaemia in pregnancy is rare, ${ }^{1}$ with few centres having extensive experience of caring for mother and fetus in this difficult situation. Ideally, management requires a team approach involving obstetricians, haematologists, and neonatal paediatricians. Cytotoxic drugs have theoretical risks of teratogenesis if administered to pregnant women in the first trimester, but in practice this risk has been shown to be small. ${ }^{2}$ It seems likely, therefore, that this will encourage women receiving chemotherapy, even during the early stages of pregnancy, not to undergo therapeutic abortion. This, coupled with a good chance of achieving remission of acute leukaemia, means that it is important that possible major fetal complications of such treatment are made known.

\section{Case report}

A 36 year old pregnant woman presented at 25 weeks of gestation, complaining of tiredness, sore gums, and easy bruising. A full blood count showed anaemia and thrombocytopenia, and bone marrow examination confirmed acute myeloid leukaemia. She began chemotherapy with cytosine arabinoside (1 $\mathrm{g} / \mathrm{m}^{2} /$ day $\left.\mathrm{D} 1-3\right)$, daunorubicin (45 $\mathrm{mg} / \mathrm{m}^{2} /$ day $\left.\mathrm{D} 1-3\right)$, and etoposide (400 $\mathrm{mg} / \mathrm{m}^{2} /$ day $\mathrm{D} 8-10$ ), achieving remission by 30 weeks. Serial ultrasound scanning showed

Circulating haemopoietic progenitor

\begin{tabular}{|c|c|c|c|c|c|c|}
\hline \multirow[b]{2}{*}{ Day } & \multicolumn{4}{|c|}{ Number of colonies/ml } & \multicolumn{2}{|c|}{$\begin{array}{l}\text { Liquid culture cells/ml } \\
\left(\times 10^{3}\right)\end{array}$} \\
\hline & $C F U-G M$ & $B F U-e$ & $B F U-M K$ & CFU-MK & ${ }^{\star} M e g a-b$ & †Mega \\
\hline $\begin{array}{l}\text { Birth } \\
5 \\
12 \\
33 \\
\text { Laboratory range: } \\
\text { Gestational age } \\
28-32 \text { weeks }\end{array}$ & $\begin{array}{c}697 \\
1904 \\
\text { ND } \\
961\end{array}$ & $\begin{array}{l}1376 \\
3024 \\
\mathrm{ND} \\
1663\end{array}$ & $\begin{array}{l}\text { ND } \\
\text { ND } \\
241 \\
226\end{array}$ & $\begin{array}{l}\text { ND } \\
\text { ND } \\
2648 \\
1939\end{array}$ & $\begin{array}{r}44.9 \\
176.9 \\
293.5 \\
193.8\end{array}$ & $\begin{array}{l}7.92 \\
31.6 \\
15.5 \\
21.5\end{array}$ \\
\hline
\end{tabular}

${ }^{\star}$ Mega-b=megakaryoblasts; †Mega = megakaryocytes; ND - not done. no fetal abnormalities, but no fetal growth was seen from 30-32 weeks. At 32 weeks she also experienced no fetal movements for one day, with cardiotocography showing unprovoked fetal heart rate decelerations, suggesting fetal distress. The woman had completed her second course of chemotherapy 11 days before and was clinically well with rising blood counts (haemoglobin of $114 \mathrm{~g} / \mathrm{l}$, a white cell count of $2.0 \times 10^{9} / 1$ (neutrophils $0.8 \times 10^{9} /$ ), and a platelet count of $\left.117 \times 10^{9} / 1\right)$. She therefore proceeded to have an emergency caesarean section. A live girl was delivered, who was immediately noted to be very pale and required active resuscitation. Birth weight was $1460 \mathrm{~g}$ (10th centile). Cord blood count confirmed anaemia and also demonstrated leucopenia with profound neutropenia (haemoglobin of $60 \mathrm{~g} / 1$ (reticulocytes $1 \cdot 3 \%$ ), a white cell count of $2.0 \times 10^{9} / 1$ (neutrophils $1 \%$ ), and a platelet count of $\left.290 \times 10^{9} / 1\right)$. She required ventilation for 10 hours while the anaemia was corrected by transfusion of packed cells. At 30 hours she developed a fever and because of persisting neutropenia (white cell count of $2 \cdot 2 \times 10^{9} / 1$ - neutrophils $1 \%$ ) and developing thrombocytopenia (platelet count of $129 \times 10^{9} / 1$ ) was given two doses of granulocyte colony stimulating factor (G-CSF) $10 \mu \mathrm{g} / \mathrm{kg}$ subcutaneously. Screening for septicaemia showed no infection and the haematological abnormalities resolved by day 4. A cerebral ultrasound scan was normal and the rest of her neonatal course was uneventful. Erythropoietin was given for anaemia of prematurity, but at current follow up (one year) she remains well, is off all treatment, and has normal peripheral blood counts. Following delivery the woman completed her chemotherapy and has now received an autologous bone marrow transplantation.

\section{CIRCULATING HAEMOPOIETIC PROGENITOR} CELLS

The baby's bone marrow activity was assessed by assaying circulating haemopoietic progenitor cells at birth, and on days 5,12 , and 33. (Circulating progenitors reflect bone marrow progenitors and hence indirectly bone marrow activity. ${ }^{3}$ ) The progenitors assayed were: CFU-GM, which are the precursors of granulocytes/monocytes; BFU-e, the precursors of erythroid cells; BFU-MK and CFU-MK, the earliest precursors of megakaryocytes; and megakaryoblasts (mega-b), which give rise to megakaryocytes. Results are summarised in the table. 


\section{Discussion}

Although a number of centres have described their experience of cytotoxic chemotherapy in pregnancy, ${ }^{24}$ there is very little information in these reports about the haematological status of the babies. We know of only one previous case report in which the blood count changes were documented. ${ }^{5}$ (The baby had isolated neutropenia and the baby's bone marrow status was not assessed.)

In this case the baby developed pancytopenia within 30 hours, and circulating haemopoietic progenitor cell studies confirmed marrow suppression: CFU-GM were reduced at birth, consistent with the severe neutropenia. They increased to above normal levels by day 5 . While this may have been due to the administration of G-CSF, it is more likely to have been the result of a rebound phenomenon as occurs in adults after chemotherapy. BFU-e were towards the lower end of our normal range at birth but doubled in the first five days of life. This contrasts with the usual pattern in which the number of BFU-e is highest in the first 24 hours of life and falls during the following week. At birth numbers of cultured megakaryoblasts and megakaryocytes were severely reduced. We have found that this predicts the development of thrombocytopenia during the first week of life. ${ }^{6}$ All progenitor markers had returned to normal by day 33.

We believe this is the first neonatal case of its kind to be investigated by serial study of the three main types of haemopoietic progenitor. The data show that the baby's marrow was actively regenerating after an acute insult. In this instance cytotoxic chemotherapy given to the mother caused fetal marrow suppression, roughly equal to the extent seen in the mother. This may have been due to the use of etoposide in this case, a relatively new antineoplastic agent which crosses the placenta and is particularly myelosuppressive. It is also highly mutagenic, ${ }^{7}$ raising the possibility of late treatment induced leukaemia in this baby.

This case illustrates that severe fetal marrow suppression may occur if women receive full dose cytotoxic chemotherapy during pregnancy. Any decision to expedite delivery in this situation should take into account the possible haematological status of the fetus (which, if appropriate, could be assessed by cordocentesis). At birth the baby may have severe haematological abnormalities, require immediate resuscitation, and ongoing neonatal intensive care. After the neonatal period repeated follow up of the baby is essential, in view of the possible long term effects of cytotoxic agents.

All obstetricians, haematologists, and neonatal paediatricians involved in the care of such pregnant women should be aware of the potential risks to the fetus, ensure that delivery and neonatal care take place in an appropriate setting, and subsequently plan careful long term follow up of the baby.

We gratefully acknowledge the support of Action Research in the development of the megakaryocyte progenitor assay systems the development of the $m$
used in this investigation.

We also acknowledge the help of Dr Ruth Warwick, consulWe also acknowledge the help of Dr Ruth Warwick, consul-
tant haematologist, National Blood Transfusion Service, tant haematologist, National Blood Transfusion Service,
Colindale Avenue, London, Dr R Jan-Mohammed, consultant haematologist, Hillingdon Hospital, Uxbridge, Middlesex.

1 Slade R, James DK. Pregnancy and maternal malignant haematological disorders. In: Turner TL, ed. Perinatal haematological problems. Chichester: John Wiley \& Sons Ltd, 1991: 23-38.

2 Aviles A, Dias-Maqueo JC, Talavera A, Guzman R, Garcia EL. Growth and development of children of mothers treated with chemotherapy during pregnancy: Current treated with chemotherapy during pregnancy: Curren
status of 43 children. Am $\mathscr{f}$ Hematol 1991; 36: 243-8.

status of 43 children. Am $\mathcal{F}$ Hematol 1991 ; 36: 243-8.
3 Urabe A. Murphy MJ, Haghbin M, Gee TS. Erythroid rabe A. Murphy MJ, Haghbin M, Gee TS. Erythroid
progenitors (BFU-e and CFU-e) in acute leukemia. $\mathcal{f}$ Clin Pathol 1979; 32: 666-9.

4 Roy V, Gutteridge CN, Nysenbaum A, Newland AC. Combination chemotherapy with conservative obstetric management in the treatment of pregnant patients with acute myeloblastic leukemeatment of pregnant patients with acute myeloblastic leukemia. Clin Lab Haematol 1989; 11: 171-8. effects of maternal cancer chemotherapy. Case report. Brf
Obstet Gynaecol 1989; 96: 1099-100.

6 Anonymous. Abstract. Early Hum Devel 1994; 36: 228.

7 Pedersen-Bjergaard J, Daugaard G, Hansen SW, Philip P Pedersen-Bjergaard J, Daugaard G, Hansen SW, Philip P,
Larsen SO, Rørth M. Increased risk of myelodysplasia and leukemia after etoposide, cisplatin, and bleomycin for germ-cell tumours. Lancet 1991; 338: 359-63.

\title{
Poor prognosis after prolonged ventilation for bronchopulmonary dysplasia
}

\author{
Mary Wheater, Janet M Rennie
}

\begin{abstract}
Of 47 babies mechanically ventilated for more than 27 days for bronchopulmonary dysplasia 20 eventually died. There were no neurodevelopmentally intact survivors among those who were ventilated for more than $\mathbf{5 0}$ days. Days of ventilation more powerfully predicted outcome than ultrasound evidence of brain injury.

(Arch Dis Child 1994; 71: F210-F211)
\end{abstract}

Prolonged neonatal mechanical ventilation is an indicator of poor prognosis, but there are
Correspondence to: Dr Rennie.

Accepted 19 July 1994 few estimates of the likelihood of normal survival. Overstreet et al studied 144 infants requiring more than 30 days' mechanical ventilation. ${ }^{1}$ Survival to discharge was related to duration of ventilation, with $90 \%$ mortality for babies ventilated for more than 120 days. Long term survival and neurodevelopmental outcome were not reported.

Ventilation for more than 21 days was a powerful predictor of developmental delay at 18 months in infants with birth weights below 1201 g. $^{2}$ Luchi et al detected no relationship between duration of mechanical ventilation and neurodevelopmental outcome among 27 